\title{
Anastomotic Sinus Developed From Leakage in Rectal Cancer Resection: When Can We Reverse the Defunctioning Stoma?
}

\author{
Chang Hyun Kim \\ Department of Surgery, Chonnam National University Hwasun Hospital, Chonnam National University Medical School, Gwangju, Korea
}

\section{See Article on Page 30-35}

Anastomotic leakage is one of the most common as well as most feared complications of rectal cancer surgery. Despite the fact that many anastomotic leaks are diagnosed during the initial postoperative period, a significant number (about one-third) become apparent at the time of assessment of anastomotic integrity, before stoma takedown as an anastomotic sinus [1]. However, literature on the optimal management of an anastomotic sinus is scarce $[2,3]$. Once an anastomotic leak has matured into a chronic sinus, plausible treatment options are: (1) delaying ileostomy takedown in anticipation of spontaneous healing; (2) reoperative anastomosis; (3) performing a permanent colostomy; (4) laying open the sinus tract into the neorectum (by deroofing of the sinus tract) [4]; and sealing the sinus tract using fibrin glue [5]. If not adequately treated, may cause more severe complications such as hydronephrosis, osteomyelitis, necrotizing fasciitis around the perirectum, and even malignancy in the epithelium of the sinus $[2,6]$.

Previously, there has been confirmative data showing that delaying stoma takedown could increase the spontaneous healing rate. Arumainayagam et al. [2] suggested that spontaneous healing of an anastomosis sinus can take 1 year; however, it is unlikely to occur after this time period. Reoperative surgery for an anastomotic leak has a success rate of $80 \%$ [7]. The incidence rate of major morbidity after redo surgery, however, is $16 \%$. In addition, pelvic sepsis (16\%), surgical reintervention (11\%), and fecal incontinence (17\%) are complications of this treatment. Fibrin glue may also be

Correspondence to: Chang Hyun Kim, M.D.

Department of Surgery, Chonnam National University Hwasun Hospital, Chonnam National University Medical School, 322 Seoyang-ro, Hwasun 58128, Korea

Tel: +82-61-379-7646, Fax: +82-61-379-7661

E-mail:drkhr@jnu.ac.kr

ORCID code: https://orcid.org/0000-0002-1954-189X

(C) 2019 The Korean Society of Coloproctology

This is an open-access article distributed under the terms of the Creative Commons Attribution NonCommercial License (http://creativecommons.org/licenses/by-nc/4.0) which permits unrestricted noncommercial use, distribution, and reproduction in any medium, provided the original work is properly cited. considered another option to fill the sinus cavity. Unfortunately, this method is effective only for a relatively small-sized sinus [5]. Finally, effectively draining the abscess can induce shrinkage of the sinus cavity and therefore performing diverting stoma takedown and avoiding an unnecessary watch and wait strategy is less invasive. This is done by deroofing the sinus [4], performing the endosponge technique using low-vacuum suction through a sponge [8], marsupialization of the neorectum and sinus using electrocautery or an endoscopic gastrointestinal stapler [4], and digital dilation of the sinus opening. If these treatment options are carefully selected, the success rate can be comparable to those of treatments with relatively few complications.

In terms of selecting patients who may be good candidates for these less invasive treatments, the size of the sinus was suggested to be the most important factor. This was based on a previous study that used the Delphi research method to obtain consensus on this issue [9]. Recently, one study has been published suggesting that the length and the radiologic morphology of the sinus, as well as width, are important factors for more sophisticated patient treatment [10]. They categorized the opening size as small $(<1 \mathrm{~cm})$ and large $(\geq 1 \mathrm{~cm})$. The length of the sinus was measured using a gastrografin enema, with a cutoff value of $5 \mathrm{~cm}$. The shape of the sinus was classified as linear, tubular, or concave. On the basis of this classification, of the 14 patients who were diagnosed as having an anastomotic sinus, 7 patients underwent ileostomy takedown in a planned schedule. The remaining 7 also had an ileostomy takedown using digital dilation of the sinus opening.

In conclusion, effective draining of the abscess can be useful in the management of patients who have suffered from an anastomotic sinus. Ileostomy takedown also can be performed even if the sinus does not completely heal. However, because anastomotic sinuses change gradually and sometimes can be aggravated even after successful healing, a longer follow-up period is required to reach a meaningful conclusion.

\section{CONFLICT OF INTEREST}

No potential conflict of interest relevant to this article was reported. 


\section{REFERENCES}

1. Borstlap WA, Westerduin E, Aukema TS, Bemelman WA, Tanis PJ; Dutch Snapshot Research Group. Anastomotic leakage and chronic presacral sinus formation after low anterior resection: results from a large cross-sectional study. Ann Surg 2017;266:870-7.

2. Arumainayagam N, Chadwick M, Roe A. The fate of anastomotic sinuses after total mesorectal excision for rectal cancer. Colorectal Dis 2009;11:288-90.

3. Hain E, Maggiori L, Manceau G, Zappa M, Prost à la Denise J, et al. Persistent asymptomatic anastomotic leakage after laparoscopic sphincter-saving surgery for rectal cancer: can diverting stoma be reversed safely at 6 months? Dis Colon Rectum 2016;59:369-76.

4. Whitlow CB, Opelka FG, Gathright JB Jr, Beck DE. Treatment of colorectal and ileoanal anastomotic sinuses. Dis Colon Rectum 1997;40:760-3.

5. Swain BT, Ellis CN. Fibrin glue treatment of low rectal and pouchanal anastomotic sinuses. Dis Colon Rectum 2004;47:253-5.

6. Sloothaak DA, Buskens CJ, Bemelman WA, Tanis PJ. Treatment of chronic presacral sinus after low anterior resection. Colorectal Dis 2013;15:727-32.

7. Westerduin E, Klaver CE, van Geloven AA, Westerterp M, Bemelman WA, Tanis PJ. Outcome after redo surgery for complicated colorectal and coloanal anastomosis: a systematic review. Dis Colon Rectum 2018;61:988-8.

8. Weidenhagen R, Gruetzner KU, Wiecken T, Spelsberg F, Jauch KW. Endoluminal vacuum therapy for the treatment of anastomotic leakage after anterior rectal resection. Rozhl Chir 2008;87: 397-402.

9. Phitayakorn R, Delaney CP, Reynolds HL, Champagne BJ, Heriot AG, Neary P, et al. Standardized algorithms for management of anastomotic leaks and related abdominal and pelvic abscesses after colorectal surgery. World J Surg 2008;32:1147-56.

10. Chung CT, Baek SJ, Kwak JM, Kim J, Kim SH. Anastomotic sinus that developed from leakage after a rectal cancer resection: should we wait for closure of the stoma until the complete resolution of the sinus? Ann Coloproctol 2019;35:30-5. 